\title{
BIOMECHANICAL TESTING OF SPINAL SEGMENT FIXED BY THORACOLUMBAR SPINE LOCKING PLATE ON THE SWINE LUMBAR SPINE
}

\author{
Jan Kocis ${ }^{\mathrm{a} *}$, Tomas Navrat ${ }^{\mathrm{b}}$, Zdenek Florian $^{\mathrm{b}}$, Peter Wendsche ${ }^{\mathrm{a}}$ \\ a Department of Traumatology, Faculty of Medicine, Masaryk University Brno, Czech Republic \\ ${ }^{b}$ Institute of Solid Mechanics, Mechatronics and Biomechanics, Faculty of Mechanical Engineering, Brno University \\ of Technology \\ E-mail:jankocis@seznam.cz
}

Received: September 22, 2010; Accepted: November 16, 2010

Key words: Biomechanics/Thoracolumbar fracture/Spine stabilization/Anterior stabilization

Background. The aim of the experiment was to compare the mechanical properties of intact spinal segment with impaired intervertebral disc and impaired intervertebral disc fixed by TSLP (Thoracolumbar Spine Locking Plate).

Methods and results. Spinal specimens were taken from domestic swine. A total of 8 test mechanical states (intact, impaired and fixed) were modeled and the mechanical properties, expressed by the value of moment of couple necessary to twist the specimen at tensile force $\mathrm{F}=200 \mathrm{~N}$ and the value of moments necessary for extension straining, were determined. The study was based on in vitro biomechanical testing of the TSLP plate used to stabilize the front thoracolumbar column of spinal segments taken from a pig. The plate was used for monosegmental fixation. The disc was cut by scalpel to simulate the Type A injury to front spinal column. In each state (intact, impaired or fixed), specimens were subjected to a tension load of prescribed force and, then, twisted by a given angle. Subsequently, extension load of intact, impaired and impaired \& fixed segment was measured. Statistical evaluation verified the hypothesis of the different behavior of intact, impaired and fixed specimens - both for tension \& torsion load and extension load. The analyses did not indicate different mechanical behavior of intact and fixed specimens. In other words, monosegmental fixation of both impaired and intact specimens by TSLP Synthes implant will lead to similar mechanical behavior of these specimens. Further, we found that intact and fixed specimens show non-symmetric behavior at positive and negative twisting angles. This was not observed for impaired specimens.

Conclusion. Several stabilization systems were developed to stabilize the front thoracolumbar spinal column. Surgery of the anterior column of injured spine should restore the correct position of the spine, ensure decompression of vertebral canal when neural structures are compressed, and stabilize the spine to allow immediate loading and mobilization of the patient. The aim of this study was to compare mechanical properties of intact spinal segment, impaired spinal segment and impaired spinal segment stabilized by TSLP Synthes implant. The problems were solved by experimental modeling using a testing machine that simulated loads for several mechanical states of the spinal segment. Favorable mechanical properties of TSLP Synthes fixator were demonstrated. The experimental results will be used for subsequent computational modeling of the spinal segment in all experimentally solved states.

\section{INTRODUCTION}

Anterior spinal fixation is commonly used to manage fractures, tumors and deformities of the spinal column and has become an increasingly accepted method. The influence of additional dorsal structure damage on anterior stabilization of the thoracolumbar fracture is still unknown. The reconstruction of the anterior column of the thoracolumbar spine has become more common in the last few years owing to disappointing results of exclusively posterior treatment that produce lack of about ten degrees of kyphosis correction after removal of the instrumentation ${ }^{1}$.There have been many biomechanical studies evaluating spinal reconstruction methods in corporectomy models ${ }^{2,3}$. Much of the biomechanical testing of spinal implants has used in vitro models ${ }^{4-6}$. Animal spines have been used as they are easier to obtain than human spines and can be selected by age and comparable size. Little has been written however about the similari- ties between human and swine spines ${ }^{7}$. The aim of the experiment was to compare mechanical properties of intact spinal segment with impaired intervertebral disc and impaired intervertebral disc fixed by TSLP Synthes. The experiment was done at the Institute of Solid Mechanics, Mechatronics and Biomechanics, Faculty of Mechanical Engineering, Brno where test specimens were prepared as well.

\section{MATERIALS AND METHODS}

\section{Preparation of test specimens}

Eight spines from 16 week old domestic swines provided by a local butcher were tested in this study. The thoracolumbar spine was dissected and frozen fresh at $-20{ }^{\circ} \mathrm{C}$. Before testing, the specimens were thawed and all musculature was carefully removed so that the ligamentous and bony structures were not damaged. The spines 


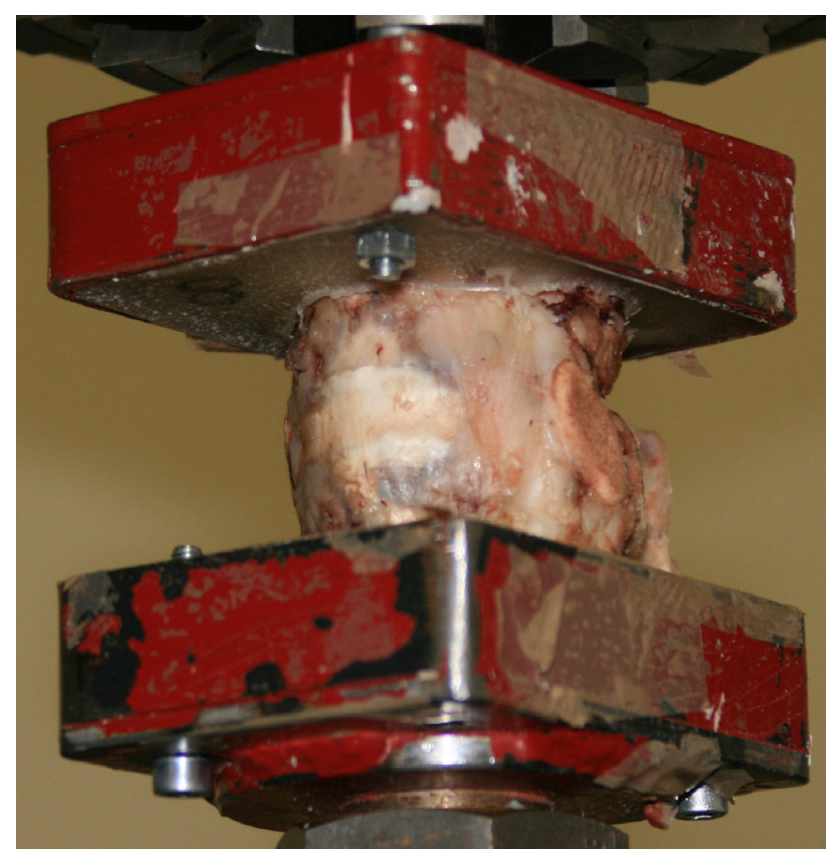

Fig. 1. Intact specimen.

were then cut into single-joint segments, each consisting of two vertebrae with intervertebral disc, facets and ligaments. For the purposes of mechanical tests, the spinal segment had to be modified so that it could be tightened into jaws of a testing machine. As the specimens were of organic origin, it was not possible to use fixtures designed for tests of technical materials. Both for testing of spinal fixators and determining mechanical properties of spinal segment, imbedding the specimens in plastic (particularly duracryl) proved very useful. Both ends of the specimen were imbedded in duracryl blocks that were tightened through plates with clamping pins into the jaws of a standard testing machine using six-jaw lathe chucks. A total of 8 test mechanical states (intact, impaired and fixed) were modeled and mechanical properties, expressed by the value of moment of a couple necessary to twist the specimen at tensile force $\mathrm{F}=200 \mathrm{~N}$ and the value of moments necessary for extension straining, were determined (Fig. 1, 2, 3). The study is based on in vitro biomechanical testing of the TSLP plate being used to stabilize front thoracolumbar column of spinal segments taken from swine. The plate was used for monosegmental fixation. The disc was cut by scalpel to simulate the Type A injury of a front spinal column. In each state (intact, impaired and fixed), specimens were subjected to a tension load of a prescribed force and then twisted by a given angle. Subsequently, extension loads of intact, impaired and impaired \& fixed segment were measured. Statistical evaluation of the measured values verified the hypothesis of different behavior of intact, impaired and fixed specimens - both for tension $\&$ torsion load and extension load.

\section{Description of TSLP Synthes}

The Thoracolumbar Spine Locking Plate (TSLP) is a versatile, low profile plating system indicated for anterior stabilization of the thoracic and lumbar spine. The system

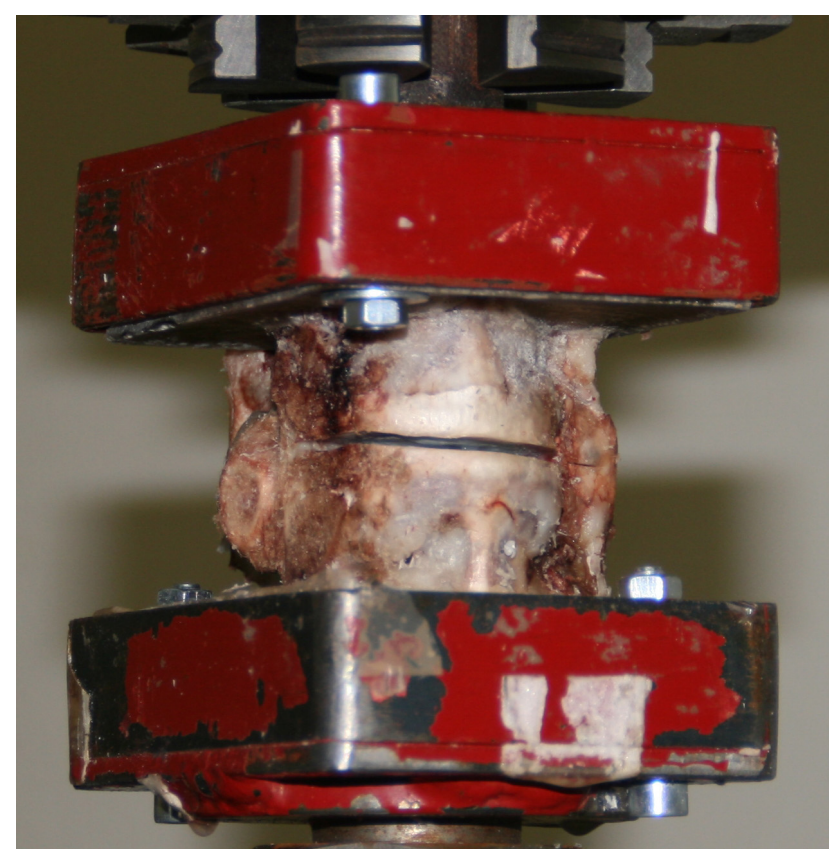

Fig. 2. Impaired specimen.

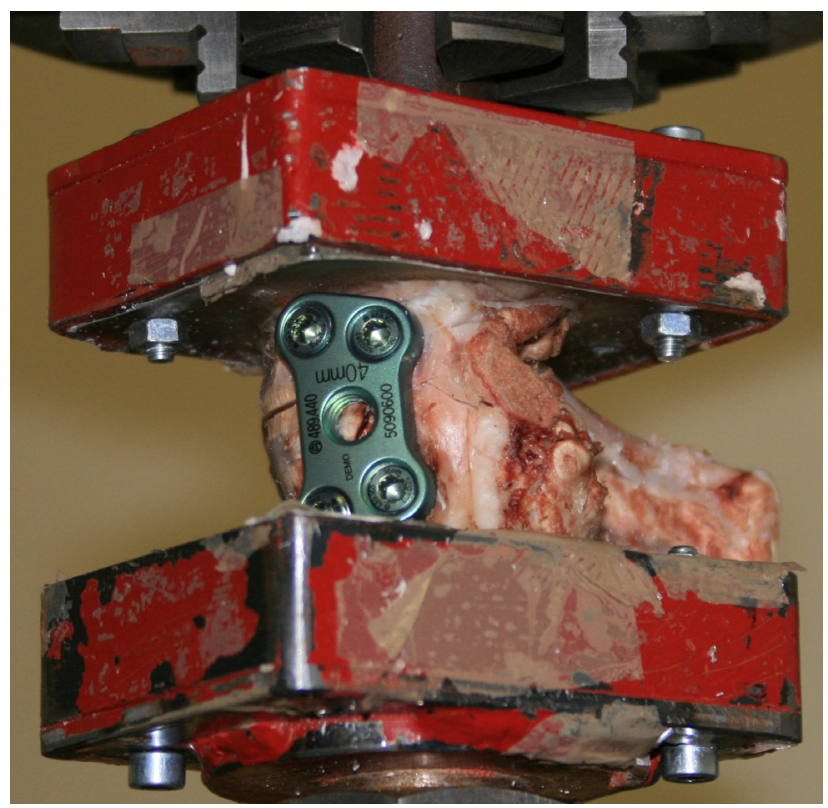

Fig. 3. Stabilized spinal segment by TSLP Synthes.

provides a $4.5 \mathrm{~mm}$ construct profile, plate lengths from $40 \mathrm{~mm}$ to $109 \mathrm{~mm}$ in $3 \mathrm{~mm}$ increments, 5.5 cancellous locking screws and instrumentation designed to simplify construct placement. The TSLP Synthes is indicated for use via the lateral or anterolateral surgical approach in the treatment of thoracic and thoracolumbar spine instability.

\section{Description of the tests and presentation of measurement results \\ Load of the specimens: TENSION + TORSION}

The Zwick testing machine with basic equipment made it possible to subject specimens to tension or torsion load, or the combination of both. Our Institute has rich experi- 


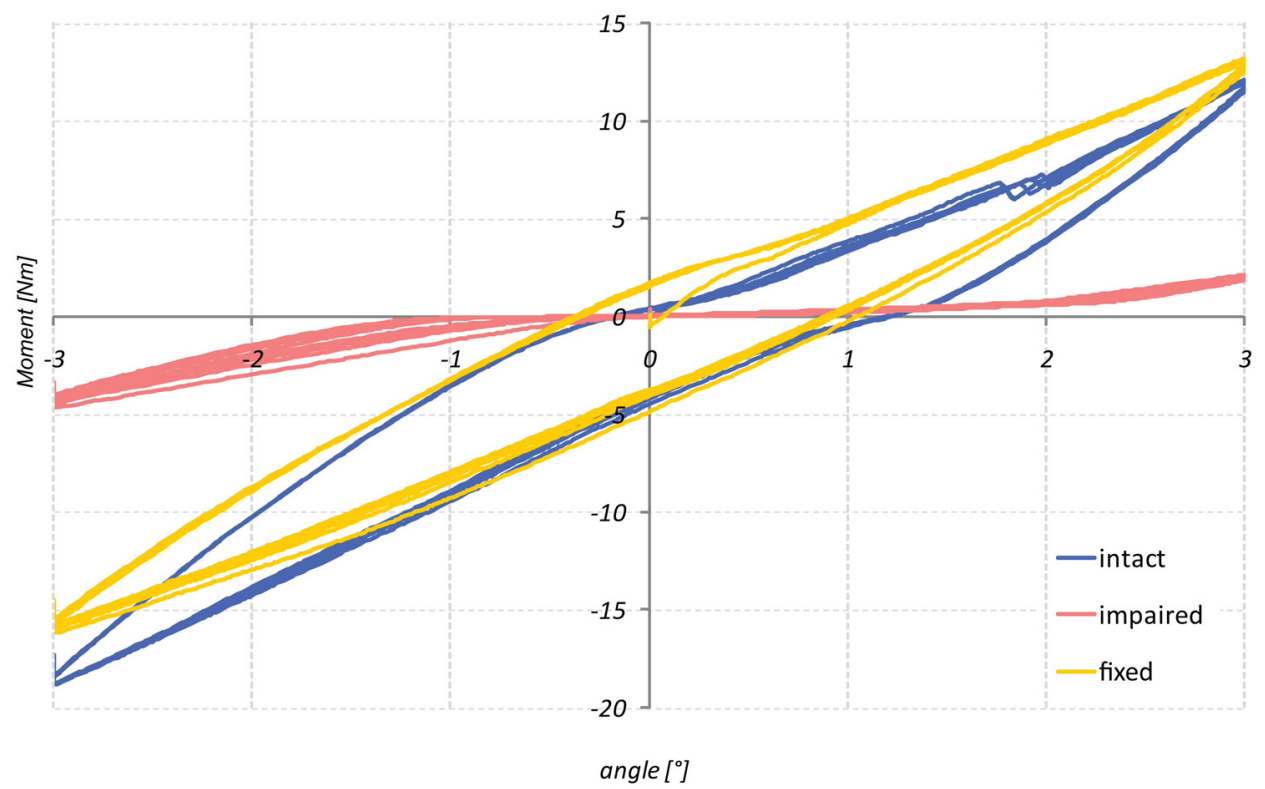

Fig. 4. Dependence of couple moment on twisting angle, specimen 4.

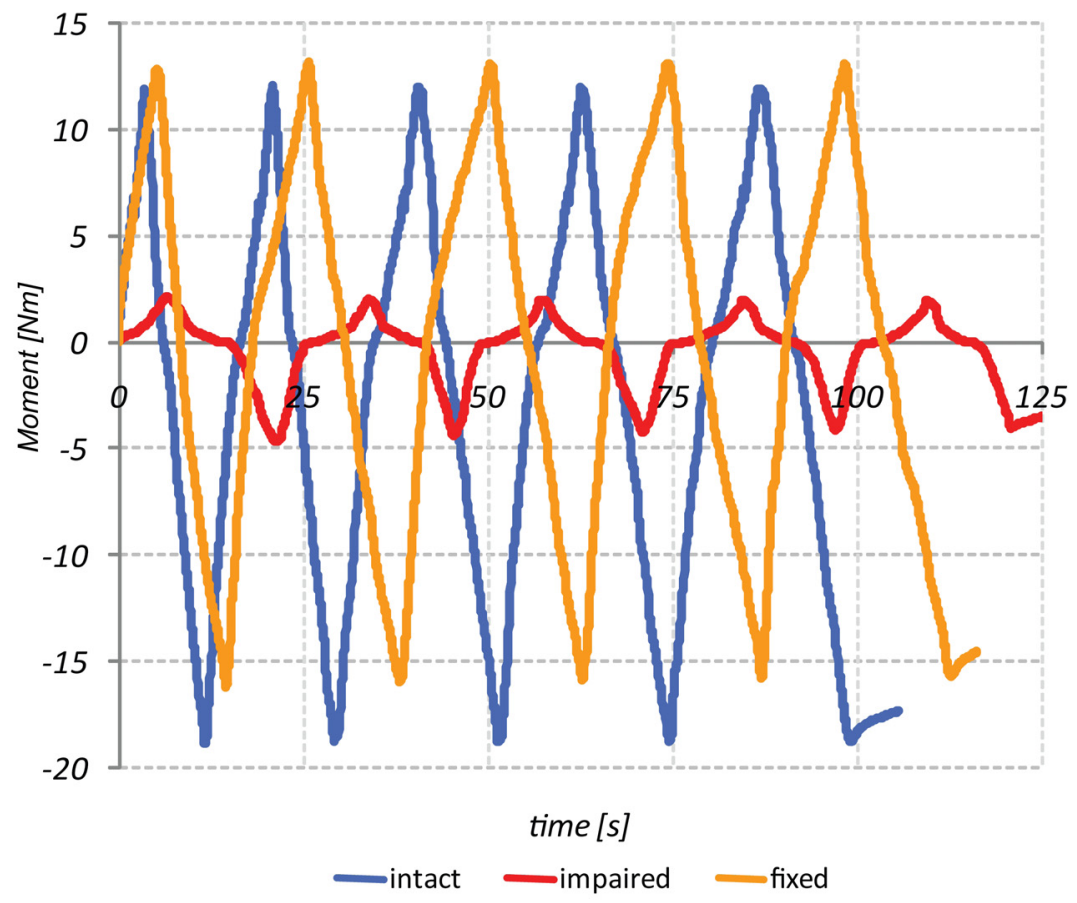

Fig. 5. Dependence of couple moment on time, specimen 4.

ence with this combination of loads used for experimental modeling of spinal elements. The tension load selected for this experiment is rather unusual, as it almost does not occur during normal movements of the human body. However, the tension load was suitable for the purpose of the experiment, as it exposed the specimen to more demanding mechanical states than pressure loads. During measurements, the spinal segment was subjected to loads that induced states of instability and also states that arose from stabilization by the implant. In each state, the specimen was subjected to a tension load of prescribed force and, subsequently, twisted by a given angle. Load values chosen were based on the experience with measurements of similar nature. The force load was $\mathrm{F}=200 \mathrm{~N}$. Torsion load had a deformation character, i.e. control variable was twisting angle and measured variable was the moment of a couple (angle $\varphi= \pm 3^{\circ}$ was used). The angle value established was based on the initial tests with regard to a maximum allowed torque of $20 \mathrm{Nm}$ (as limited by the sensor). A total of 8 specimens were prepared for the purposes of the experiment. During measurements, values of couple necessary to twist the specimens were evaluated. 
Table 1. Values of moment [Nm] necessary to twist the specimens by $\pm 3^{\circ}$, state: 1 - intact, 2 - impaired, 3 - stabilized.

\begin{tabular}{|c|c|r|r|r|r|r|r|r|r|}
\hline \multirow{2}{*}{$\begin{array}{c}\text { Specimen } \\
\text { state }\end{array}$} & \multirow{2}{*}{$\begin{array}{c}\text { Twisting } \\
\text { angle [ }\end{array}$} & \multicolumn{9}{|c|}{ Specimen } \\
\cline { 3 - 10 } & 1 & 2 & 3 & 4 & 5 & 6 & 7 & 8 \\
\hline \multirow{3}{*}{1} & +3 & 10.1 & 10.6 & 12.6 & 13.1 & 12.1 & 11.5 & 5.8 & 13.8 \\
\cline { 2 - 11 } & -3 & -13.2 & -14.9 & -17.9 & -14.3 & -18.8 & -14.9 & -10.2 & -17.2 \\
\hline \multirow{3}{*}{2} & +3 & 3.0 & 5.3 & 2.4 & 3.4 & 2.1 & 4.3 & 1.9 & 6.2 \\
\cline { 2 - 10 } & -3 & -3.4 & -5.2 & -3.2 & -3.4 & -4.6 & -6.2 & -3.1 & -4.0 \\
\hline \multirow{3}{*}{3} & +3 & 7.1 & 9.5 & 13.3 & 8.6 & 13.2 & 13.6 & 12.0 & 15.0 \\
\cline { 2 - 10 } & -3 & -14.7 & -15.4 & -18.9 & -13.1 & -16.1 & -16.2 & -11.8 & -15.9 \\
\hline
\end{tabular}

Table 2. Two-Sample T-test.

\begin{tabular}{|l|c|c|c|}
\hline Specimen state & Intact & Impaired & Fixed \\
\hline p-values & 0.010 & 0.423 & 0.010 \\
\hline $\begin{array}{l}\text { At the level of significance of a }=0.05, \\
\text { the null hypothesis is }\end{array}$ & rejected & not rejected & rejected \\
\hline
\end{tabular}

Table 3. Non-parametric Kruscal-Wallis test.

\begin{tabular}{|l|c|c|c|}
\hline Specimen state & Intact & Impaired & Fixed \\
\hline p-values & 0.009 & 0.318 & 0.021 \\
\hline $\begin{array}{l}\text { At the level of significance of a }=0.05, \\
\text { the null hypothesis is }\end{array}$ & rejected & not rejected & rejected \\
\hline
\end{tabular}

An example of the behavior of force couple moment in relation to twisting angle for Specimen 4 is demonstrated in (Fig. 4). By way of contrast, dependences of couple moment on time are illustrated in (Fig. 5).

\section{Measured values}

Maximum couple values to ensure $+3^{\circ}$ and $-3^{\circ}$ torsion are summarized in (Table 1 ). The measured maximum moments are divided into three classes according to the specimen state and summarized in (Fig. 6) where interval estimates of mean values for each class are specified as well. It has to be decided whether the differences between classes are statistically significant or, in other words, whether the impairment of specimens and the application of fixators affect the intensity of the moment necessary to twist the specimens. Analysis of variance was used to evaluate the differences.

\section{Verification of data normality}

P-value chosen was $>0.05$. At the level of significance of $\alpha=0.05$, the hypothesis of normal distribution of data was accepted.

\section{Comparison of variances in individual classes (Bartlett's Test)}

The hypothesis that measurements in all classes had the same variance about the mean was tested. At the level of significance of $\alpha=0.05$, the hypothesis that data variability in all classes were the same, i.e. $p$-value $=0.196$, was not rejected.

Testing of equality of mean values for classes "intact", "impaired" and "fixed" specimen (One-way ANOVA)

Based on the variance analysis, at the level of significance of $\alpha=0.05$ the hypothesis that mean values were equal for twisting angles $+3^{\circ}$ and $-3^{\circ}(p$-value $=0.000)$ was rejected. ANOVA can be used to calculate interval estimates of the difference between mean values for all couples of classes. If an interval estimate of the difference between mean values does not include 0 , then there is a statistically significant difference between mean values of classes. Interval estimates of the difference between mean values indicate a statistically significant difference between class "intact" and "impaired" and class "impaired" and "fixed".

To make the analysis complete, non-parametric tests were used as well. 
$95 \%$ confidence intervals for mean value

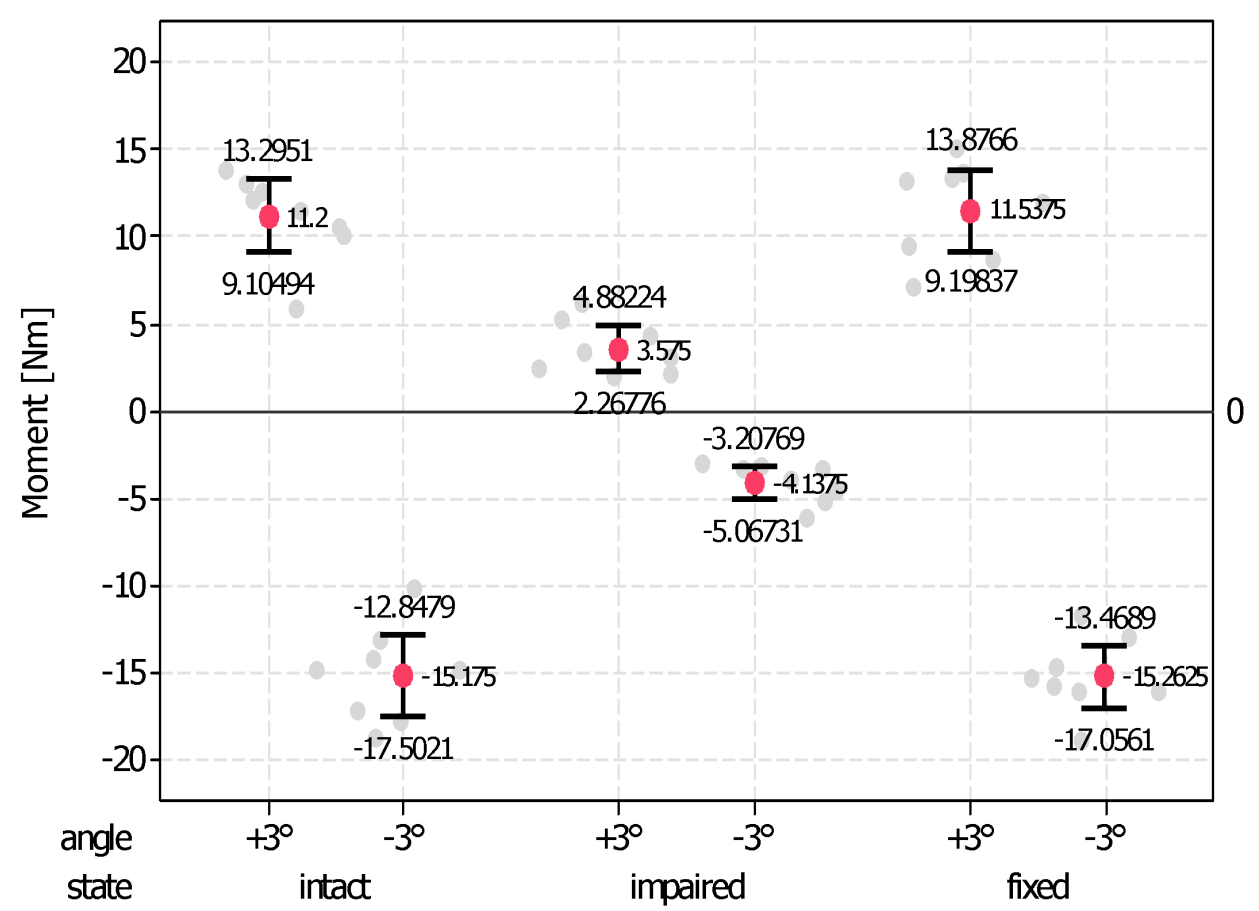

Fig. 6. Interval estimates of mean values with 0.95 confidence; red points - mean value, grey points - measured values.

Equality of medians was tested using Kruskal-Wallis test for "intact", "impaired" and "fixed" specimen classes.

At the level of significance of $\alpha=0.05$, the hypothesis that medians in all classes were equal for twisting angles $+3^{\circ}$ and $-3^{\circ}(p$-value $=0.001, p$-value $=0.000)$ was rejected .

"Impaired" class was removed and the test was repeated. Equality of medians by Kruskal-Wallis test for "intact" and "fixed" classes was then tested.

At the level of significance of $\alpha=0.05$, there was no significant difference in medians between "intact" and "fixed" classes (for twisting angle $+3^{\circ} \mathrm{p}$-value $=0.674$, for twisting angle $-3^{\circ} \mathrm{p}$-value $\left.=0.916\right)$. Only median of "impaired" specimen class was different.

\section{Testing of symmetrical behavior of specimens}

\section{Two-Sample T-Test}

For each state, the measured moment values were divided according to the twisting angle $\left(+3^{\circ}\right.$ and $\left.-3^{\circ}\right)$ into two classes. The hypothesis was tested that two samples had the same mean value.

Null hypothesis $\mathrm{H}_{0}: \mu_{1}=\mu_{2}$, alternative hypothesis $\mathrm{H}_{1}$ : $\mu_{1} \neq \mu_{2}$ (Table 2).

\section{Non-parametric Kruskal-Wallis test}

For each state, the measured moment values were divided according to the twisting angle $\left(+3^{\circ}\right.$ and $\left.-3^{\circ}\right)$ into two classes. The hypothesis was tested that two samples had the same median.

Null hypothesis $\mathrm{H}_{0}: \mu_{1}=\mu_{2}$, alternative hypothesis $\mathrm{H}_{1}$ : $\mu_{1} \neq \mu_{2}$ (Table 3).

\section{Specimen load: EXTENSION}

As no special testing machine for modeling of the load produced by extension and flexion movements was available, a dedicated fixture was designed and fabricated that could be used with a standard testing machine. Using this fixture, the specimen is loaded by force couples during a classic tension test. According to the specimen position in the fixture, these couples should simulate flexion, extension or lateral bending. The fixture is demonstrated in (Fig. 7,8) where the evaluated parameters are highlighted (particularly the value of force $\mathrm{F}$ and the displacement of the machine crossbeam $u$ ).

If external elements of the fixture tightened in the testing machine chuck are loaded by force $F(F=200 N)$, the upper and lower plates are loaded by two forces.

$\mathrm{F}_{\mathrm{s}}=\mathrm{F} / 2=200 / 2=100 \mathrm{~N}$ that make a couple with $\mathrm{M}=$ $F_{s} \cdot d=100 \cdot 0,11=11 \mathrm{Nm}$. This load simulates loading of the specimen during extension movement and, when the specimen is turned in the fixture, also flexion movement.

Modeled states of the specimens (Fig. 9,10,11).

- Intact specimen - healthy

- Impaired specimen - after resection and decompression

- Fixed impaired specimen - fixed by TSLP Synthes

Measurement procedure:

- The specimen is fixed in the fixture in such a manner as to be loaded in extension

- The fixture with intact specimen is loaded by force $\mathrm{F}=200 \mathrm{~N}$. The displacement of the testing machine crossbeam u was read. 

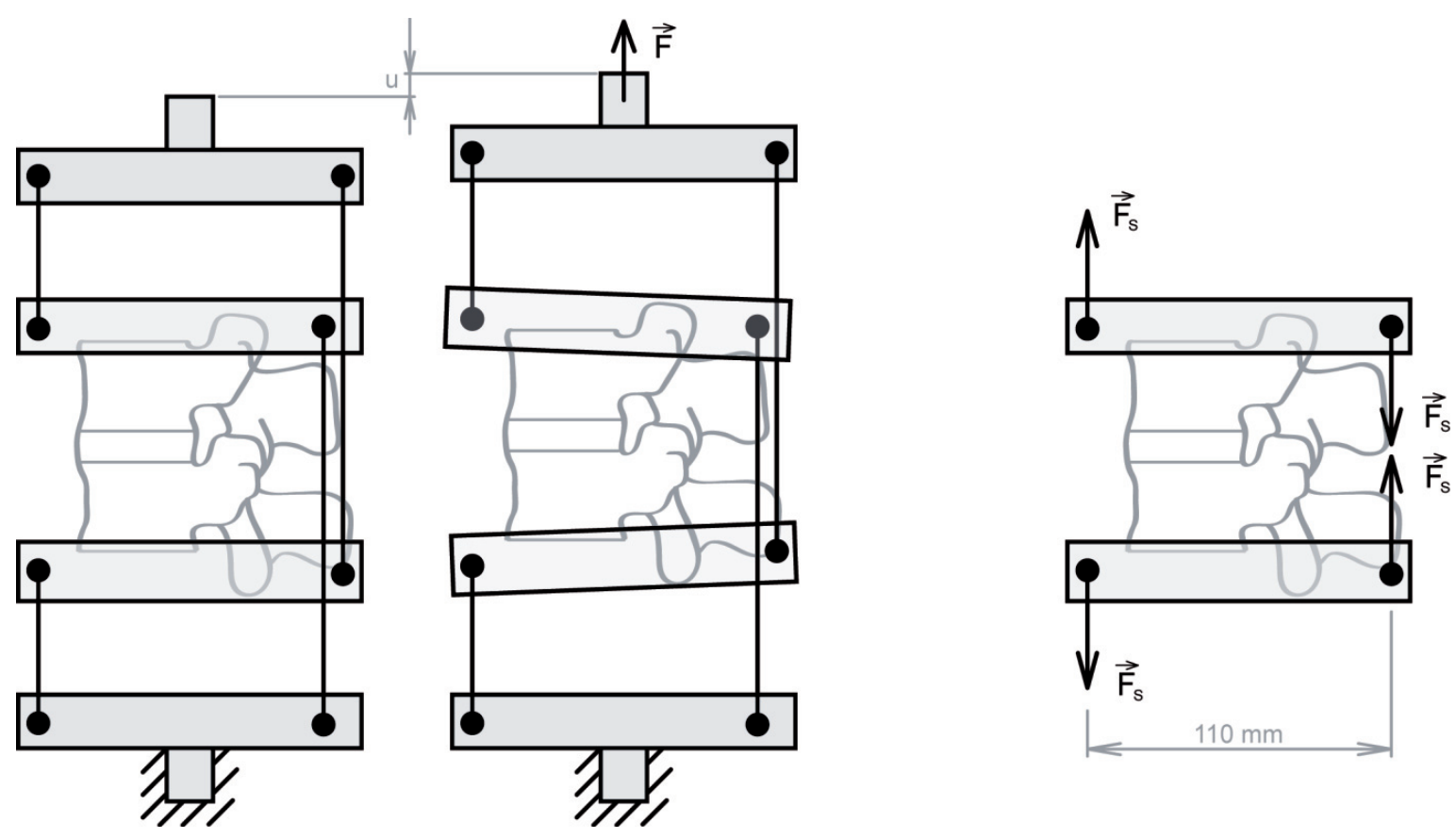

Fig. 7. The fixture with specimen-loaded/ unloaded.
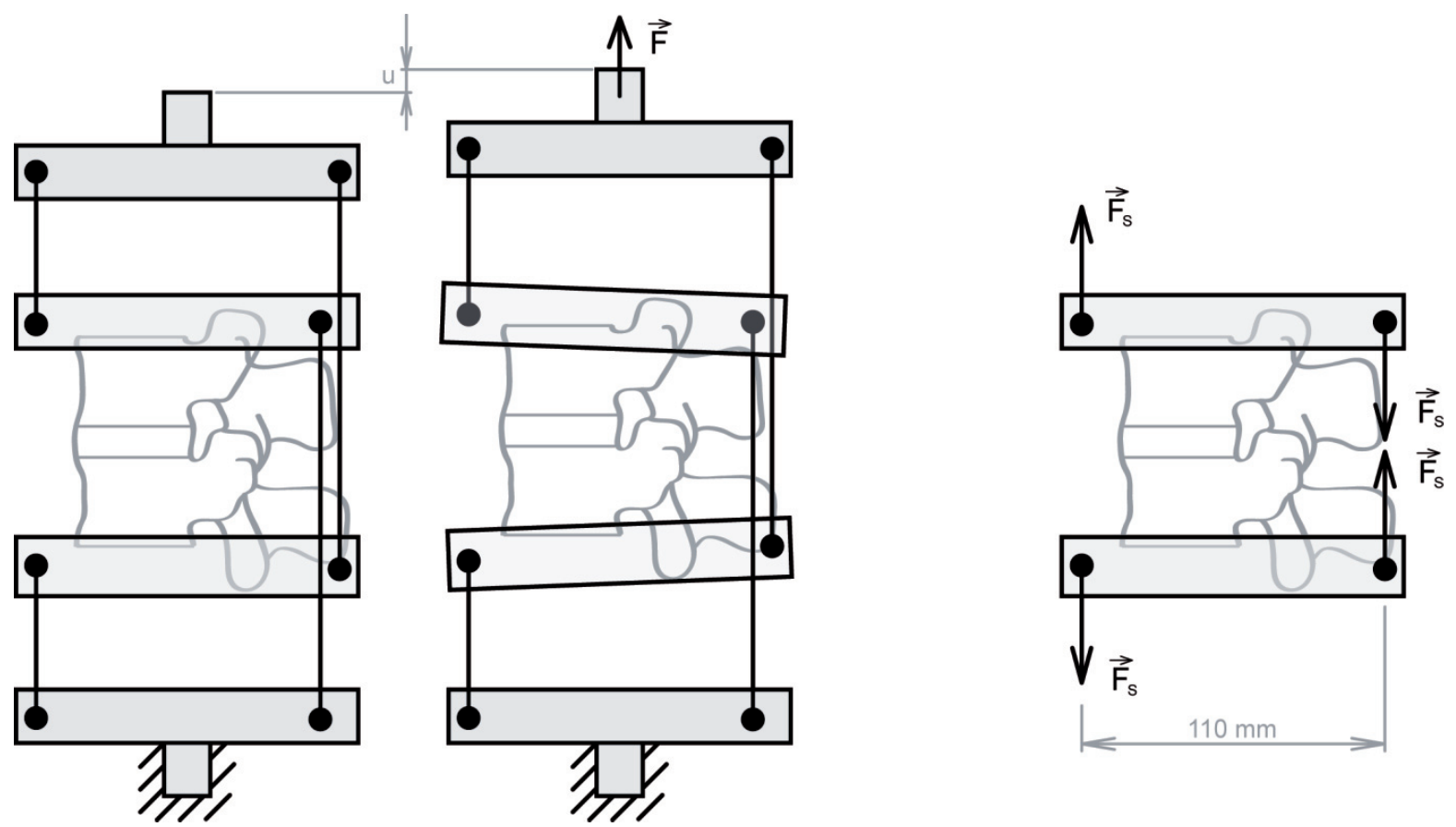

Fig. 8. The specimen is released.

- Impaired specimen is loaded by displacement to the value corresponding with the displacement $u$ in the intact specimen.

- Fixed specimen is strained to the value corresponding with the displacement $\mathrm{u}$ in the intact specimen.

Fixed specimen is loaded by force $F=200 \mathrm{~N}$.

Values of force and crossbeam displacement were used to compare each modeled state of specimens. The correlation between load force $\mathrm{F}$ and the displacement of the testing machine crossbeam is insignificant for the comparison. Therefore only discrete values measured according to the scenario described above are evaluated. The measured values of force and strain parameters for seven specimens, each tested in three states, are summarized in (Table 4). Forces $F$ were converted to the corresponding values of couples that were further used for statistical evaluation (printed bold in Table 4). Moment values (printed bold in Table 4), divided to three classes according to the state of the specimen, are summarized in (Fig. 12) where also interval estimates of mean values of individual classes are plotted on. It has to be decided whether the differences between classes are statistically 


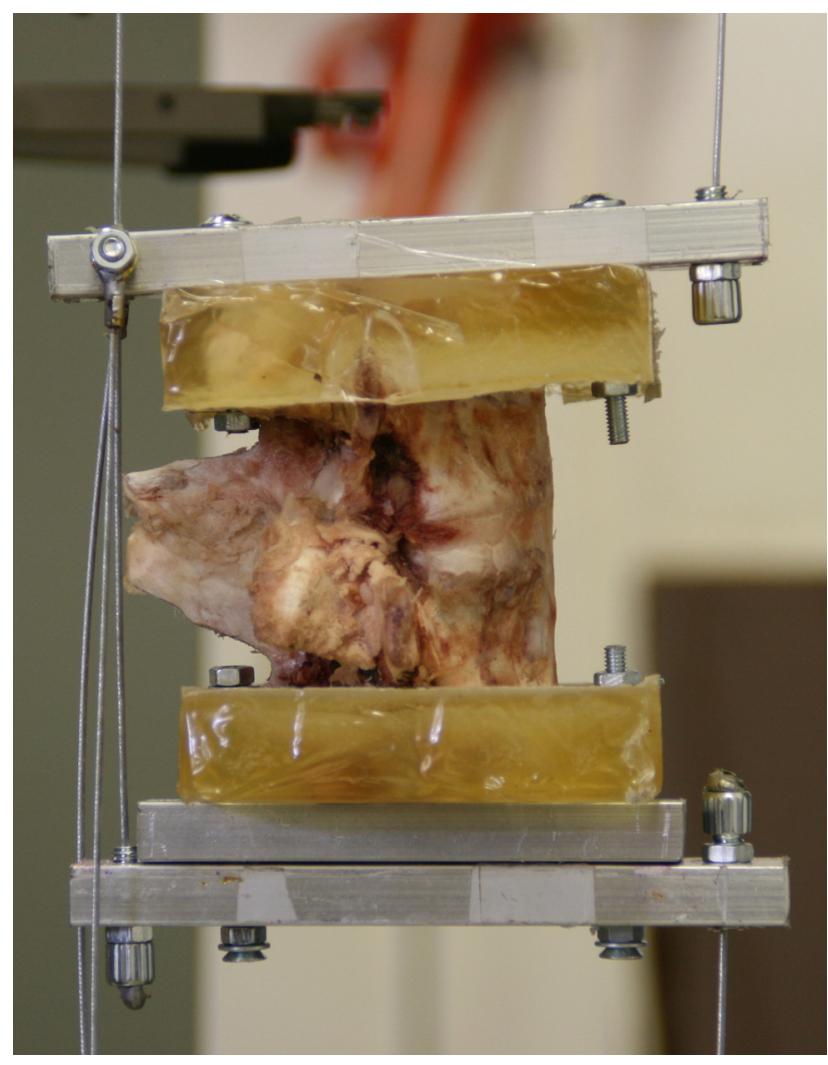

Fig. 9. Intact specimen.

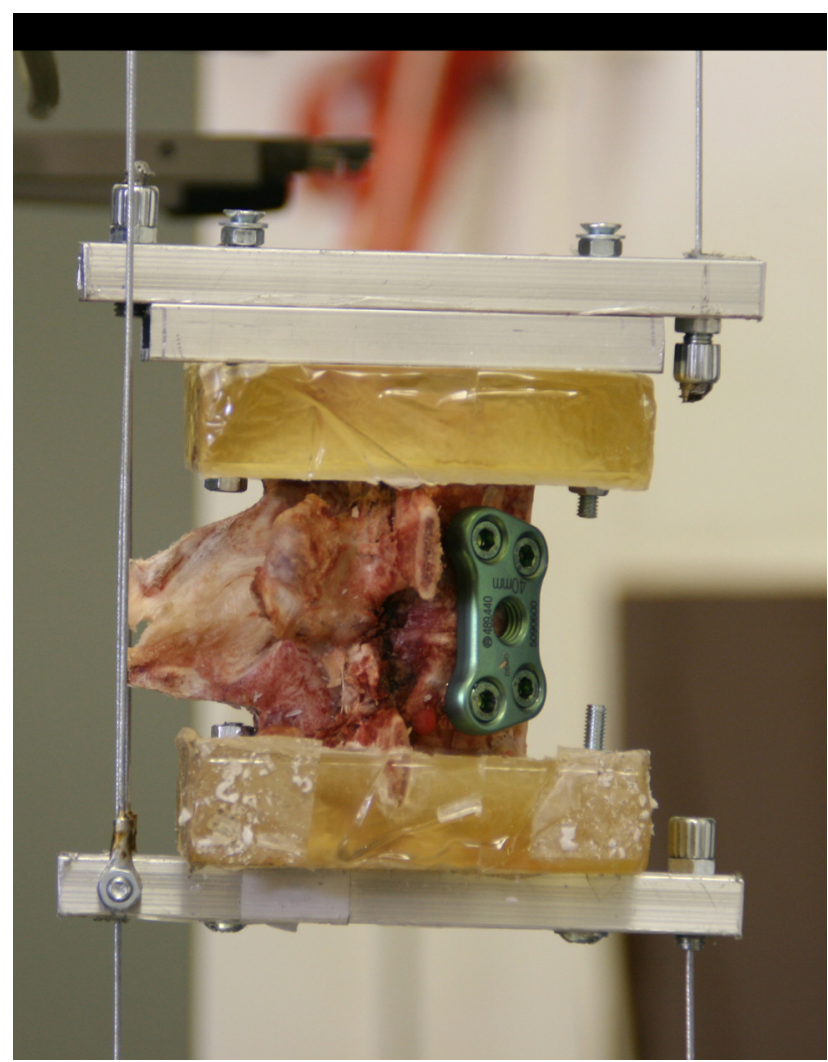

Fig. 11. Stabilized specimen.

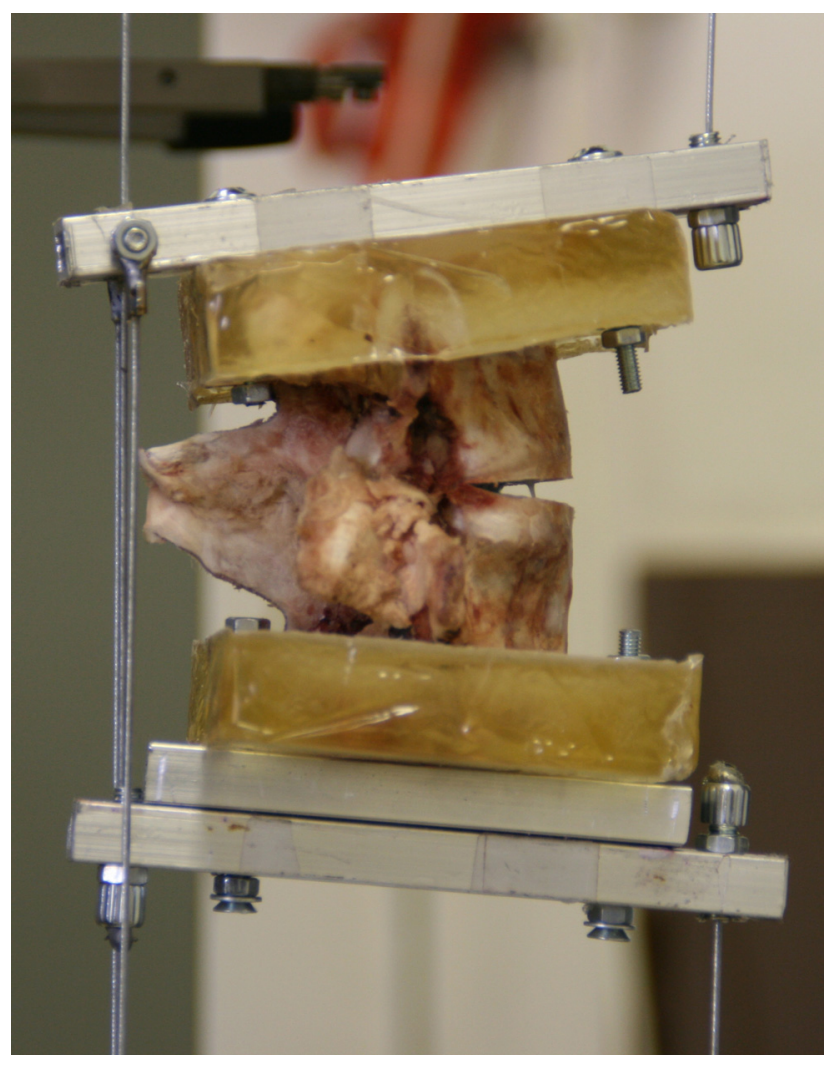

Fig. 10. Impaired specimen.

significant or, in other words, whether the impairment of specimens and the application of fixators affects the intensity of the moment necessary to twist the specimens. A statistical test was used to evaluate the differences.

\section{Verification of data normality}

P-values for all samples are $>0.05$. At the level of significance of $\alpha=0.05$, the hypothesis of normal distribution of data was not rejected.

\section{Testing of equality of variances of samples}

The hypothesis that measurements in all classes had the same variance about the mean was tested. At the level of significance of $\alpha=0.05$, the hypothesis of equality of data variances in all classes, i.e. p-value $=0.556$, was not rejected.

\section{Testing of mean values}

Impaired specimens: At the level of significance of $\alpha$ $=0.05$, the hypothesis of $\mu=11 \mathrm{Nm}$, $\mathrm{p}$-value $=0.004<\alpha$ was rejected.

Fixed specimens: At the level of significance of $\alpha=$ 0.05 , the hypothesis of $\mu=11 \mathrm{Nm}$, p-value $=0.28>\alpha$ was not rejected.

The hypothesis of equality of mean values in "impaired" and "fixed" classes is tested (t-test). At the level of significance of $\alpha=0.05$, the hypothesis of equality of mean values, $\mathrm{p}$-value $=0.003<\alpha$, was rejected.

\section{Summary of results}

The calculated p-values for tests of equality of mean values (Table 5) 
$95 \%$ confidence intervals for mean value

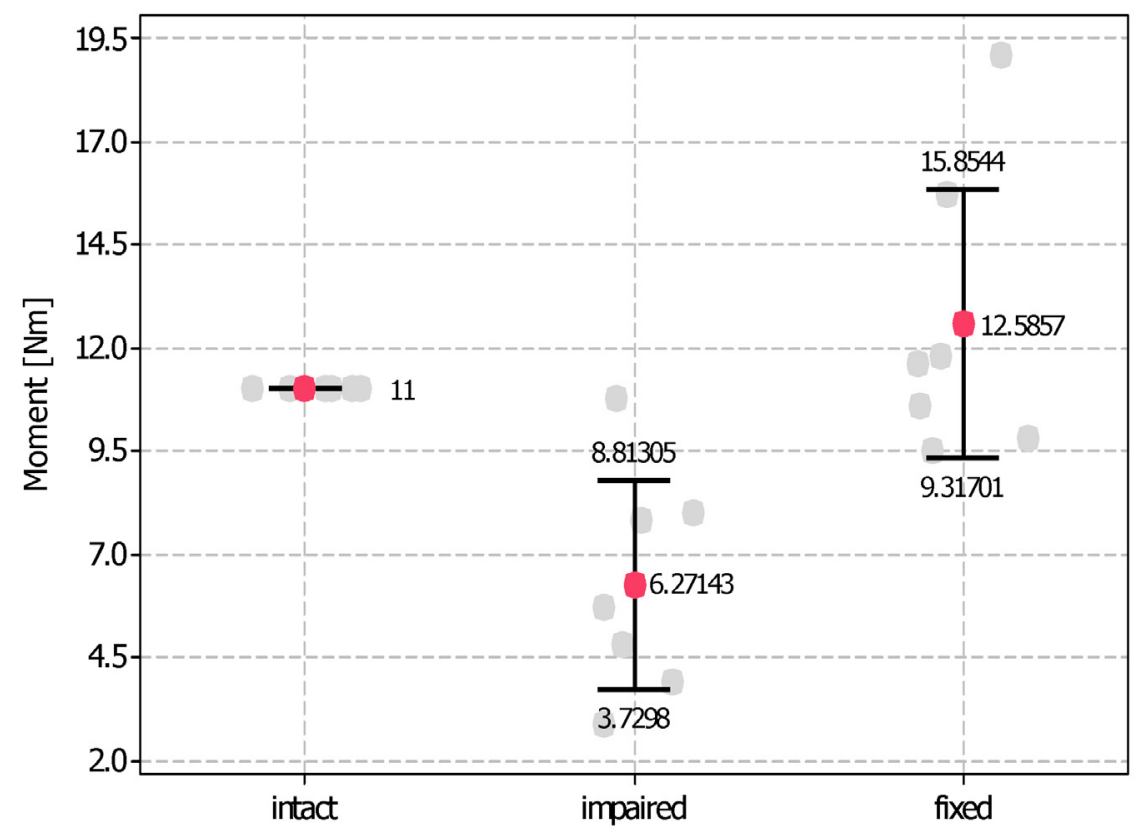

Fig. 12. Interval estimates of mean values with 0.95 confidence; red points - mean value, grey points - measured values (Specimen state).

In bold combinations, the hypothesis of equality of mean values at the level of significance of $\alpha=0.05$ was rejected.

To make the analysis complete, non-parametric tests were used as well.

The hypothesis of equality of medians of individual classes is tested (Kruskal-Wallis test).

At the level of significance of $\alpha=0.05$, the hypothesis that medians are the same in all classes $(p$-value $=0.002)$ was rejected.

"Impaired" specimen class was removed. Then it was tested whether the median of "fixed" class was 11 (the value of moment in "intact" class).

At the level of significance of $\alpha=0.05$, there was no significant difference in medians between classes "intact" and "fixed" ( $p$-value $=1.0$ ). Only median of "impaired" class was different.

\section{DISCUSSION}

Axial forces acting on the spine are transmitted by $80-85 \%$ through the anterior column. Many pathologies of the vertebral column including trauma, metastasis or infection can compromise the integrity of the vertebral body, leading to an unstable situation causing neurologic deficits in some cases. Posterior stabilization in unstable injuries of the thoracolumbar spine is regarded as a standard procedure ${ }^{1,7}$. On the basis of clinical and biomechanical investigations, a number of authors now advocate reconstructing the axial load - bearing ability of the anterior spine using different materials for vertebral body replacement ${ }^{2-5}$. The primary stability of ventral fixation system has been improved over the past years and special implants supporting minimally invasive procedures have been developed. Biomechanical testing is important for preclinical evaluation of new implant system and surgical procedures. The demand for human cadaveric spines for this purpose, however, exceeds the available resources. One solution is the substitution of animal spines for those of humans ${ }^{8}$. Calf spines are most widely used substitute for human spines for in vitro testing, possibly because their anatomy seems to approximate that of the human spine ${ }^{9}$. In this study the mechanical properties of a thoracoscopically implantation thoracolumbar instrumentation system were considered. We confirmed the initial hypothesis that the anterior stabilization system improves primary stability and has advantage of an improved endoscopic implantation procedure. Several investigators have looked at the anterior thoracolumbar fixation device. Anterior instrumentation for the thoracolumbar spine has evolved rapidly in recent years. Modern designs such as the Kaneda device, TSRH system, Z- plate are becoming more popular because of the biomechanical stability of the construction and their user-friendliness ${ }^{10-12}$. In the beginning of thoracolumbar fracture treatment, the established standard instrumentation was performed after the initial or intermittent dorsal intervention and reduction and secondary mono or bisegmental ventral stabilization ${ }^{13}$. Sufficient mechanical stability of anterior spinal instrumentation is of crucial importance, especially in minimally invasive spine surgery, without additional dorsal fixation ${ }^{6}$. For the purposes of this study, 8 test specimens were prepared that were used to simulate three mechanical states (intact, impaired and fixed). Further, 
Table 4. Measured values.

\begin{tabular}{|c|c|c|c|c|c|}
\hline \multirow{2}{*}{ Specimen } & \multirow{2}{*}{ Value } & \multicolumn{4}{|c|}{ Specimen state } \\
\hline & & \multirow{2}{*}{$\frac{\text { Intact }}{200}$} & \multirow{2}{*}{$\begin{array}{c}\text { Impaired } \\
103\end{array}$} & \multicolumn{2}{|c|}{ Fixed } \\
\hline \multirow{3}{*}{1} & force $[\mathrm{N}]$ & & & 215 & 200 \\
\hline & displacement [mm] & 4.9 & 4.9 & 4.9 & 3.5 \\
\hline & moment $[\mathrm{Nm}]$ & 11.0 & 5.7 & 11.8 & 11.0 \\
\hline \multirow{3}{*}{2} & force $[\mathrm{N}]$ & 200 & 146 & 348 & 200 \\
\hline & displacement [mm] & 7.8 & 7.8 & 7.8 & 4.4 \\
\hline & moment $[\mathrm{Nm}]$ & 11.0 & 8.0 & 19.1 & 11.0 \\
\hline \multirow{3}{*}{3} & force $[\mathrm{N}]$ & 200 & 53 & 173 & 200 \\
\hline & displacement [mm] & 5.1 & 5.1 & 5.1 & 5.6 \\
\hline & moment $[\mathrm{Nm}]$ & 11.0 & 2.9 & 9.5 & 11.0 \\
\hline \multirow{3}{*}{4} & force $[N]$ & 200 & 142 & 285 & 200 \\
\hline & displacement [mm] & 6.1 & 6.1 & 6.1 & 4.2 \\
\hline & moment $[\mathrm{Nm}]$ & 11.0 & 7.8 & 15.7 & 11.0 \\
\hline \multirow{3}{*}{5} & force $[\mathrm{N}]$ & 200 & 197 & 210 & 200 \\
\hline & displacement [mm] & 7.5 & 7.5 & 7.5 & 6 \\
\hline & moment $[\mathrm{Nm}]$ & 11.0 & 10.8 & 11.6 & 11.0 \\
\hline \multirow{3}{*}{6} & force $[\mathrm{N}]$ & 200 & 70 & 178 & 200 \\
\hline & displacement [mm] & 6.6 & 6.6 & 6.6 & 5.1 \\
\hline & moment $[\mathrm{Nm}]$ & 11.0 & 3.9 & 9.8 & 11.0 \\
\hline \multirow{3}{*}{7} & force $[\mathrm{N}]$ & 200 & 87 & 193 & 200 \\
\hline & displacement [mm] & 6 & 6 & 6 & 5.5 \\
\hline & moment $[\mathrm{Nm}]$ & 11.0 & 4.8 & 10.6 & 11.0 \\
\hline
\end{tabular}

Table 5. The calculated p-values for tests of equality for mean values.

\begin{tabular}{|l|c|c|c|}
\hline P-values & Intact & Impaired & Fixed \\
\hline Intact & - & 0.004 & 0.280 \\
\hline Impaired & 0.004 & - & 0.003 \\
\hline Fixed & 0.280 & 0.003 & - \\
\hline
\end{tabular}

the mechanical properties of the specimens were determined. They were expressed by the value of moment of couple necessary to twist the specimen at a tensile force $\mathrm{F}=200 \mathrm{~N}$ and the value of moments necessary for extension straining. Statistical evaluation of the measured values verified the hypothesis of the different behavior of intact, impaired and fixed specimens - both for tension + torsion load and extension load. The analyses do not indicate different mechanical behavior of intact and fixed specimens. In other words, fixation of both impaired and intact specimens by TSLP Synthes implant will lead to the similar mechanical behavior of these specimens. Further, we found that intact and fixed specimens showed nonsymmetric behavior at the positive and negative twisting angle. This was not observed in impaired specimens.

\section{CONCLUSION}

The aim of this study was to compare the mechanical properties of intact spinal segment and spinal segment stabilized by TSLP Synthes implant. The problems were solved by experimental modeling using a ZWICK testing machine that simulated loads for several mechanical states of the spinal segment. A dedicated fixture for simulation of flexion and extension movements was designed in such a manner so that it could be used with a standard testing machine. Despite the limited number of appropriate test specimens and a time-consuming preparation stage of the experiment, favorable mechanical properties of TSLP Synthes fixator were demonstrated. The results 
will be used for subsequent computational modeling of the spinal segment in all experimentally solved states. The data were statistically processed using MINITAB 15 software.

\section{ACKNOWLEDGEMENTS}

This study was supported by a grant of the Ministry of Education, Youth and Sports of the Czech Republic, research plan MSM 0021630518 "Simulation modelling of mechatronic systems".

\section{RERERENCES}

1. Knop C, Blauth M, Bastian L, Lange U, Kesting J, Tscherne H. Fractures of the thoracolumbar spine. Late results of dorsal instrumentation and its consequences. Unfallchirurg 1997;100:630-9.

2. Abumi K, Panjabi MM, Duranceau J. Biomechanical evaluation of spinal fixation devices. Part III. Stability provided by six spinal fixation devices and interbody bone graft. Spine 1989;14:1249-55.

3. Dick JC, Brodke DS, Zdeblick TA, Bartel BD, Kunz DN, Rapoff AJ.Anterior instrumentation of the thoracolumbar spine. A biomechanical comparison. Spine 1997;22:744-50.

4. Flamme $\mathrm{CH}$, Hurschler C, Heyman C, Von Der Heide N. Biomechanical testing of different ventral fixation devices on the bovine lumbar spine. Z Orthop Ihre Grenzgeb 2004;142:88-96.
5. Vesely R, Florian Z, Wendsche P, Tosovsky J. Biomechanical evaluation of the modular anterior construct system (MACS ${ }^{\mathrm{TM}}$ ) internal fixator for thoracic spinal stabilization. Acta Vet. Brno 2008;77:97-102.

6. Wenger DR, Carollo JJ, Wilkerson JA, Wauters K, Herring JA. Laboratory testing of segmental spinal instrumentation versus traditional Harrington instrumentation for scoliosis treatment. Spine 1982;7:265-269.

7. Wilke HJ, Krischek S, Claes L. Biomechanical comparison of calf and human spines. J Orthop Res 1996;14:500-503.

8. Fricka KB, Mahar AT, Newton PO. Biomechanical analysis of anterior scoliosis instrumentation: differences between single and dual rod systems with and without interbody structural support. Spine 2002;27:702-6.

9. Cotteril PC, Kostuik JP, D’Angelo G, Fernie GR, Maki BE. An anatomical comparison of the human and bovine thoracolumbar spine. J Orthop Res 1986;4:298-303.

10. Gurr KM, McAfee PC, Shih CM. Biomechanical analysis of anterior and posteriori instrumentation system after corpectomy. A calf-spine model. J Bone Joint Surg Am 1988;70:1182-1191.

11. Kotani Y, Cunningham BW, Parker L, Kanayama M, McAfee P. Static and fatique biomechanical properties of anterior thoracolumbar instumentation systems using a synthetic model. Spine 1999;14:1406-1413.

12. Zdeblick TA, Warden KE, Zou D, McAfee PC, Abitbol JJ. Anterior spinal fixators. A biomechanical in vitro study. Spine 1993;18:513517.

13. Buhren V, Beisse R, Potulski M. Minimally invasive ventral spondylodesis in injuries to the thoracic and lumbar spine. Chirurg 1997;68:1076-1084. 